\title{
Educação, transmissão e cultura: as cantigas tradicionais como legado histórico-cultural no contexto escolar
}

\begin{abstract}
Resumo: Este artigo busca debater as cantigas tradicionais na escola como forma de transmissão de um legado histórico-cultural, partindo do conceito de educação proposto por Hannah Arendt e da noção de alegria na escola de Georges Snyders. Por meio da revisão bibliográfica e análise do pensamento de ambos os autores acerca do sentido da atividade educativa, da função social e política da escola e da concepção de tradição e cultura, pretende-se dissertar sobre a importância da transmissão de um patrimônio histórico-cultural, oriundo dos saberes e conhecimentos populares, do qual as cantigas tradicionais fazem parte. Hannah Arendt compreende a educação como atividade de inserção e de iniciação das novas gerações no mundo por meio da transmissão de saberes, hábitos, valores e conhecimentos. Snyders, por seu turno, pensa a escola como um espaço social e cultural em que ocorre o contato da criança com a cultura elaborada e com as tradições. Isso, para o autor francês, é o que caracterizaria a escola como um universo específico, no qual, pela disciplina e pelo esforço intelectual, se teria acesso à alegria do conhecimento e à satisfação da cultura. Diante dessa aproximação do pensamento de Arendt e de Snyders é que se conclui que, em face da ruptura do fio da tradição no mundo moderno, a transmissão de saberes e práticas lúdicas da cultura popular, tal como as cantigas tradicionais, é fundamental para que as novas gerações estabeleçam laços de pertencimento com o mundo e diálogo com o passado e com as gerações precedentes.
\end{abstract}

Palavras-chave: escola; cultura; cantigas tradicionais; Hannah Arendt; Georges Snyders.

\section{Apresentação}

A escola, como instituição social interposta entre a esfera privada e a esfera pública, é responsável pela inserção e transmissão de um patrimônio cultural historicamente acumulado às novas gerações. Nesse processo, o sujeito se compreende como parte de um contexto social, o qual foi tecido histórica e culturalmente, e nele pode criar laços de pertencimento. É a inserção em um mundo de significados, artefatos, hábitos, valores e objetos da cultura que possibilita que crianças e jovens, futuramente, possam renová-lo.

Partindo-se do conceito de educação proposto por Hannah Arendt e da noção de alegria na escola de Georges Snyders, este artigo se propõe a retomar o sentido das cantigas tradicionais na escola, tomando-as como objetos imateriais da cultura que possuem caráter lúdico e que, como tradições orais de diferentes comunidades,
Crislei de Oliveira Custódio Universidade Ibirapuera crislei.paula@usp.br Juliana de Almeida Carvalho Silva Universidade Ibirapuera julianadealmeidacarvalhosilva@ gmail.com 
precisam ser transmitidas para as novas gerações para que não se tornem obsoletas e caiam em esquecimento, levando consigo parte de nossos saberes tradicionais.

\section{Educação como transmissão de um patrimônio histórico-cultural e inserção no mundo}

Nesta seção, pretende-se analisar a perspectiva de Hannah Arendt acerca da educação, tema em que ela se debruça a partir da noção de crise do mundo moderno. É preciso, contudo, destacar de antemão que crise é entendida pela autora não como degeneração, mas como uma oportunidade, desde que não seja respondida com juízos e ideias pré-concebidas.

Arendt (2003) compreende a crise como a perda do senso comum, isto é, como a circunstância em que as respostas que até então eram aceitas como válidas e dotadas de sentido perdem o seu significado diante de novas perguntas ou frente às questões já existentes, mas que, no contexto de instauração da crise, foram reconfiguradas exigindo novo esforço de pensamento. Em momentos diversos de sua obra, a filósofa se dispõe a analisar os efeitos da crise sob diferentes perspectivas: a crise da cultura, as crises da república. Assim, o que a autora analisa não é uma crise da educação, mas sim a crise na educação. Ou seja, ela não se dedica a pensar possíveis crises inerentes à educação em si, mas se debruça sobre as formas por meio das quais a crise do mundo moderno produz efeitos na educação.

Para entender que efeitos são esses é preciso, porém, entender o que a autora concebe por educação. Segundo ela,

[...] a educação é uma das atividades mais elementares e mais necessárias da sociedade humana, que jamais permanece tal qual é, porém se renova continuamente através do nascimento, da vinda de novos seres humanos. Esses recém-chegados, além disso, não se acham acabados, mas em estado de vir a ser. Assim, a criança, objeto da educação, possui para o educador um duplo aspecto: é nova em um mundo que lhe é estranho e se encontra em processo de formação; é um novo ser humano e é um ser humano em formação. (ARENDT, 2003, p. 234-235)

É importante destacar que Hannah Arendt, ao falar sobre educação, ora o faz referindo-se a uma noção mais geral e pretensamente 
antropológica do termo e ora o faz tomando-a na especificidade da educação escolar. De qualquer modo, a educação, seja da perspectiva dos pais como da perspectiva dos educadores, se institui como uma atividade humana que se defronta com o duplo aspecto do nascimento: as crianças nascem para a vida, enquanto filhotes da espécie humana, e, ao mesmo tempo, nascem para o mundo, como sujeitos singulares, o que as torna um ser humano em processo de formação e um novo ser no mundo. Isso significa que ao mesmo tempo que a criança está em processo de desenvolvimento físico, motor, psíquico e intelectual e precisa ser resguardada do mundo, ela é um estrangeiro nesse mundo humano e, como tal, precisará aprender sobre os códigos sociais, a língua, as formas de se relacionar, a história e a cultura da comunidade em que ela será inserida. Do ponto de vista da vida biológica, a criança é mais um elemento da espécie humana e precisa de condições favoráveis para crescer e se desenvolver. Já do ponto de vista do mundo, a criança é um novo ser que deverá se constituir como sujeito em uma sociedade específica, sendo a sua vida e a suas experiências um fio que se tece na trama de relações humanas constituindo uma história singular.

Em Arendt (2003), o mundo se renova pela chegada de novos seres humanos que, por serem novos, chegam como estrangeiros a um ambiente no qual não se está familiarizado e do qual ainda não se faz parte. A filósofa disserta sobre o aspecto duplo que envolve a educação das crianças, o qual está relacionado com a noção de nascimento e natalidade: a criança nasce para a vida e para o mundo. Assim,

A criança partilha o estado de vir a ser com todas as coisas vivas; com respeito à vida e seu desenvolvimento, a criança é um ser humano em processo de formação, do mesmo modo que um gatinho é um gato em processo de formação. Mas a criança só é nova em relação a um mundo que existia antes dela, que continuará após sua morte e no qual transcorrerá sua vida. (ARENDT, 2003, p. 235)

De acordo com essa abordagem, o mundo preexiste à chegada da criança, mas, a partir do momento em que ela nasce, far-se-á necessário inseri-la nesse mundo, pois dele fará parte enquanto viver. Ao mesmo tempo, Arendt situa a educação como uma atividade fundamental para a preservação do mundo comum, 
afastando-a da ideia de atividade produtiva, ligada à função vital. De acordo com ela,

\begin{abstract}
Se a criança não fosse um recém-chegado nesse mundo humano, porém simplesmente uma criatura viva ainda não concluída, a educação seria apenas uma função da vida e não teria que consistir em nada além da preocupação para com a preservação da vida e do treinamento e na prática do viver que todos os animais assumem em relação a seus filhos. (ARENDT, 2003, p. 235)
\end{abstract}

Ora, a ideia de natalidade consiste, do ponto de vista da educação, em uma dimensão desse duplo nascimento: ela nasce para a vida, enquanto um filhote da espécie que crescerá e se desenvolverá como organismo vivo, e nasce em um mundo que existia antes de sua chegada, um mundo que possui cultura e história e no qual, devido à total novidade que ela representa, deverá ser inserida para que, conforme o conheça, possa sentir-se parte dele, criar laços de pertencimento e viver uma história. Nesse sentido, o nascimento de um novo ser no mundo aponta para a singularidade e unicidade desse sujeito recém-chegado: nunca houve alguém como ele e nunca haverá alguém igual após a sua partida. O nascimento no contexto do mundo comum situa o sujeito enquanto um novo começo. Assim,
A natalidade, que se revela no nascimento humano e no agir de cada ser singular na pluralidade dos homens, só é possível por habitarmos um mundo durável e que permanece como elo entre o aparecimento e o desaparecimento de cada singularidade. O Início e o ponto final de cada existência individual. (LEITE, 2016, p. 21)

A singularidade de cada sujeito e a pluralidade humana se revelam no mundo porque este é durável e permanece para além da ida e vinda de cada um. A cada nascimento, um novo ser aparece no mundo e, a cada morte, um ser único e singular desaparece do mundo. Essa novidade que denota o aparecimento e desaparecimento de cada singularidade só se faz presente no mundo humano, o qual constitui o elo que liga as novas gerações às que a antecederam e às que já estão no mundo quando da sua chegada.

Sobre essa relação entre novidade da criança e chegada a um mundo velho que a precede e que permanecerá após a sua partida, Arendt (2003) destaca a responsabilidade dos pais, ou adultos 
responsáveis, na educação das crianças. Como uma função protetiva e aparentemente conflitiva, na educação, os adultos são responsáveis por proteger a criança do mundo, e, ao mesmo tempo, proteger o mundo dessa criança, o que significa inserir a criança no mundo e garantir a continuidade dele ao mesmo tempo. Isso quer dizer que os pais humanos

[...] não apenas trouxeram seus filhos à vida mediante a concepção e o nascimento, mas simultaneamente os introduziram em um mundo. Eles assumem na educação a responsabilidade, ao mesmo tempo, pela vida e desenvolvimento da criança e pela continuidade do mundo. Essas duas responsabilidades de modo algum coincidem; com efeito podem entrar em mútuo conflito. A responsabilidade pelo desenvolvimento da criança volta-se em certo sentido contra o mundo: a criança requer cuidado e proteção especiais para que nada de destrutivo the aconteça de parte do mundo. Porém também o mundo necessita de proteção, para que não seja derrubado e destruído pelo assédio do novo que irrompe sobre ele a cada nova geração. (ARENDT, 2003, p. 235)

Se o lar e o seio familiar seriam o espaço de proteção da criança em relação ao mundo, constituindo a esfera privada, a escola é tida para Arendt como uma esfera pré-política, que estabelece a ponte onde se dá a transição entre os âmbitos privado e público. Segundo Arendt, a escola é "a instituição que interpomos entre o domínio privado do lar e o mundo com o fito de fazer com que seja possível a transição, de alguma forma, da família para o mundo". (ARENDT, 2003, p. 238)

Cabe destacar o papel dos adultos na atividade educativa como sujeitos responsáveis pela inserção das crianças e jovens no mundo e no patrimônio histórico-cultural que o compõe. Para Arendt (2003), a autoridade dos adultos se traduz na sua dupla responsabilidade - pelas novas gerações e pelo mundo. A autora elucida que a educação não pode prescindir da autoridade nem da tradição, embora a ruptura com o fio da tradição e a crise da autoridade sejam marcas do mundo moderno. Esse é o ponto nevrálgico que configura a crise na educação. No entanto, diferentemente das críticas que recaem sobre aquilo que se convencionou chamar de educação tradicional'1 , a autoridade, em Arendt, não pode ser entendida como autoritarismo. De acordo com a autora, a autoridade dos adultos toma forma na condição que eles assumem
(1) Para saber mais sobre a crítica de Arendt à pedagogia moderna e as interpretações caricaturais que, em geral, são feitas por vertentes da pedagogia nova à pedagogia tradicional, ver Custódio (2011). 
como representantes do mundo. Portanto, "[...] face à criança, é como se ele fosse um representante de todos os habitantes adultos, apontando os detalhes e dizendo à criança: - Isso é o nosso mundo". (ARENDT, 2003, p. 239)

A autoridade do professor na atividade educativa se dá, em parte, por sua competência de transmitir os conhecimentos acumulados do mundo, mas se traduz, sobretudo e por excelência, em sua condição de representante do mundo, isto é, de sujeito que representa aqueles que estão no mundo e aos antepassados frente às novas gerações. Dessa maneira,

\begin{abstract}
Na medida em que a criança não tem familiaridade com o mundo, deve-se introduzi-la aos poucos a ele; na medida em que ela é nova, deve-se cuidar para que essa coisa nova chegue à fruição em relação ao mundo como ele é. Em todo caso, todavia, o educador está aqui em relação ao jovem como representante de um mundo pelo qual deve assumir a responsabilidade, embora não o tenha feito e ainda que secreta ou abertamente possa querer que ele fosse diferente do que é. Essa responsabilidade não é imposta arbitrariamente aos educadores; ela está implícita no fato de que os jovens são introduzidos por adultos em um mundo em contínua mudança. [...] Na educação, essa responsabilidade pelo mundo assume a forma de autoridade. (ARENDT, 2003, p. 239)
\end{abstract}

A autoridade, nesse sentido, diz respeito à responsabilidade dos adultos em introduzir as crianças e jovens no mundo. Considerando que as novas gerações vêm ao mundo como estrangeiros que desconhecem a cultura, a história, a língua, o vocabulário, os hábitos e valores existentes, os adultos, em sua dupla tarefa de proteger o mundo e proteger a criança, as apresentam o que é o nosso mundo. Os adultos são, portanto, aqueles que o representam. Ser representante do mundo, porém, não implica concordar com tudo que há nele, mas, reconhecer que esse é o artefato humano, o lugar que estabelecemos na Terra para convivermos e para abrigar o patrimônio histórico-cultural que acumulamos. É por meio da inserção no mundo humano e no conjunto de significados que o constituem, bem como nas relações humanas que nele ocorrem que os recém-chegados se tornam sujeitos e estabelecem laços de pertencimento. Por essa razão que, do ponto de vista arendtiano, os adultos não podem se furtar à responsabilidade que possuem 
como representantes do mundo e responsáveis tanto pela proteção da criança quanto pela durabilidade desse mundo.

Custódio (2011), com base no pensamento arendtiano, disserta sobre o fenômeno da perda de autoridade na educação como uma expressão da crise do mundo moderno. Para além de um epifenômeno que espelharia a perda de autoridade no contexto da política moderna, a perda de autoridade em educação consiste no ponto nevrálgico da crise na educação, em especial com o advento das pedagogias renovadas do século XX que, em seu afã de modernização, passam a prescindir ou a relativizar a importância da autoridade na relação entre adultos e crianças, desconsiderando o fato de que esta não é o mesmo que autoritarismo, violência, coação ou poder.

Somado ao fenômeno da perda de autoridade, a crise se manifesta na educação moderna por meio da crise da tradição, isto é, da ascensão do pathos do novo e consequente rechaço ao passado. Ou seja, a paixão pela novidade e inovação na educação acaba por relegar à obsolescência os conteúdos do passado que constituem patrimônio e legado histórico-cultural a ser transmitido às novas gerações. Sob o imperativo do novo como sinônimo de bom e me1hor, a educação, entendida como processo de inserção e iniciação no mundo, se torna uma tarefa conflitiva, desprovida de sentido e pretensamente malograda de ponto de partida.

O fato de não prescindir da tradição exige, na concepção arendtiana, que a educação seja conservadora. No entanto, ao contrário do que se pode imaginar em um primeiro momento, ser conservadora não significa ser contrária a mudanças nem muito menos ser uma atividade reacionária. O conservadorismo ao qual se refere Arendt diz respeito à conservação. Isto é, para proteger o mundo do novo que a criança representa e, ao mesmo tempo, para inserir a criança no mundo de modo que o início e a novidade radical que ela representa possam renovar esse mundo no futuro, é preciso que a educação conserve aquilo que desejamos ser passado adiante como patrimônio histórico-cultural. Nesse sentido,

A conservação do mundo diz respeito, em parte, à inserção dos novos; entretanto, ela não consiste apenas nisso. Iniciar nossos jovens e crianças em conhecimentos, princípios e virtudes que priorizamos e consideramos importantes para serem legados contribui para a preservação do mundo. [...] Ou seja, inserir os recém-chegados no artificialismo humano, embora confira certa estabilidade ao mundo dos homens, contribui preferencialmente 
para que os novos possam 'sentir-se em casa' neste mundo e, posteriormente, por ele responder. (CUSTÓDIO, 2011, p. 108)

Leite (2016), em sua leitura da obra de Hannah Arendt e assim como Custódio (2011), destaca que a educação carrega em si um conservadorismo inerente à sua responsabilidade de zelar pela continuidade do mundo como tempo-espaço que constitui elo intergeracional e como lugar com o qual os novos precisam construir laços de pertencimento. Para que isso ocorra, é preciso que se selecione o que será conservado, ou seja, o que será legado do passado para os mais novos. Como destaca Custódio (2011, p. 109), "mais do que apresentar como tradição e de transmiti-lo como uma unidade sólida, conferir alguma durabilidade ao mundo por meio da preservação de fragmentos do passado conserva a beleza de nosso legado". Não se trata, pois, de uma transmissão irrefletida e mecânica ou da tentativa de reprodução do passado. A conservação de que fala Arendt, sobretudo em um contexto em que houve a ruptura com o fio da tradição a qual constituía o testamento que nos legava posses do passado, requer seleção e escolha. Assim, "formar nossos jovens [e crianças], nessa perspectiva, relaciona-se à seleção de pedaços preciosos do passado que, ao mesmo tempo em que conservem certa dimensão do mundo, possam ter algum sentido no presente". (CUSTÓDIO, 2011, p. 110)

É só por meio da iniciação no mundo, da inserção em nosso patrimônio histórico-cultural e da compreensão do lugar que se ocupa neste mundo e dos laços de pertença que são estabelecidos que, na concepção arendtiana, as novas gerações poderão renová-lo. Leite (2016) apresenta a renovação como capacidade humana que atravessa a continuidade dos homens no mundo e que o livra da ruína. Mas, para que essa capacidade se atualize por meio da liberdade na ação política, é necessária a atitude conservadora da educação a qual permite a durabilidade e preservação do mundo comum.

A educação precisa ter essa dimensão conservadora, então, porque é a partir da transmissão de um legado de conhecimentos, hábitos e valores constituídos e significados no passado por gerações precedentes, que o mundo pode permanecer como espaço que interliga as gerações com o passado, o presente e o futuro. Além disso, o novo só pode aparecer a partir do contato e face à compreensão do que já existia. É nesse ponto que natalidade e mundo são entendidos por Arendt como o sentido da educação: o amor ao novo que é a criança e aquilo que ela representa de singular 
para o mundo, e o amor ao mundo como construção histórica que nos liga aos nossos antepassados e à nossa possibilidade de futuro.

\section{Alegria na escola e satisfação da cultura}

Ao se abordar a educação como forma de inserção no mundo, entende-se que essa se dá a partir da transmissão de um patrimônio histórico-cultural que orienta a formação do sujeito e a criação de laços de pertença com o mundo. Isso ocorre por meio das relações sociais e intersubjetivas que se constituem, em grande parte, na escola. Embora tenha sido idealizada como instituição a qual caberia parte do papel de criar uma sociedade moderna e mais justa, a segunda metade do século XX veio demolir o mito da educação salvadora, uma vez que se constatou que, mesmo em vista da garantia do acesso universal, a escola por si só não é capaz de assegurar o desenvolvimento pleno das potencialidades de todas as pessoas e a inserção integral na sociedade de forma equilibrada.Diante dessa constatação, novos olhares e concepções sobre a escola surgem. Ao menos desde a década de 1970,

[...] estudos nas áreas de Sociologia, Filosofia, História da Educação e Didática revelaram a possibilidade de novos olhares sobre os problemas que a educação escolarizada não conseguiu ainda solucionar. Suas falhas quanto os objetivos de promover igualdade entre os indivíduos e o desenvolvimento de uma sociedade pautada por princípios de justiça e democracia acabaram por ser entendidas como uma gama de significados em produção contínua, favorecendo a exclusão das minorias e a construção de lógicas pelas quais o mundo e o homem são pensados unilateralmente e coisificados. [...] É no cerne dos debates que, no século XX, ampliaram e ressignificaram a ideia de escola Moderna que se insere a obra de Georges Snyders. (SERDEIRA, 2019, p. 190)

Georges Snyders, importante pedagogo francês do século XX, concebe a escola, de acordo com Serdeira (2019), como um universo específico. Sua reflexão sobre a função social e sentido da escola é atravessada por sua experiência de vida, a qual compreende um período nos campos de concentração em Auchwitz, em 1944. Judeu, ateu e comunista, Snyders pensará a escola, a princípio, como espaço de ofício e de luta até chegar à noção de espaço da 
alegria, repudiando veementemente, ao longo de toda a sua obra, toda forma de preconceito, xenofobia e racismo.

Para uma de suas principais comentadoras, a obra de Snyders pode ser dividida em duas fases distintas e demarcadas: uma analítica e dialógica, que propõe o debate sobre a história da pedagogia na França desde o século XVII, apresentando "uma síntese teórica em que os traços positivos das obras analisadas são assumidos como pertinentes para a pedagogia progressista e os elementos negativos são marcados como pontos de ruptura". (SERDEIRA, 2019, p. 191, grifo do autor) A segunda fase consistiria em uma extensão dos princípios e pressupostos desenvolvidos na fase inicial em que ele passa a conferir um teor mais democrático à cultura político-revolucionária e à cultura elaborada transmitida pela escola. Essa fase denota a ênfase na forma e recursos que Snyders adota para defender seus próprios princípios.

Diante do reconhecimento da potencialidade e caráter progressista da infância e da importância da cultura na formação das massas, Snyders conceberá a sua pedagogia tendo como um de seus aspectos principais a busca pela alegria do conhecimento por parte da criança, alegria essa que, em sua perspectiva, só será possível no universo específico da escola.

Para Snyders, a escola é um espaço único, dentre as instituições sociais, o qual é responsável por colocar os sujeitos em contato com a cultura de uma forma específica. O autor, ao apropriar-se dos pressupostos da escola tradicional, os ressignifica dotando-os de positividade, que toma forma no elogio à disciplina e esforço intelectuais, elementos indispensáveis para a inserção e a apropriação dos modelos da cultura elaborada. Assim, a escola é, de acordo com o pedagogo francês, o universo específico no qual a criança confronta-se com certa cultura e, por meio do trabalho do professor, desenvolve a disciplina necessária para nela imergir. É importante ressaltar que a escola, por sua vez, não é mera transmissora ou reprodutora de modelos culturais e as crianças, na perspectiva snydersiana, não são tal qual tábulas rasas: elas participam de uma cultura. Ao defender o acesso universal aos bens culturais, o autor reconhece as contradições e conflitos que marcam a instituição escolar, contudo, identifica brechas que "abrem espaço para a formação intelectual das massas e para a constituição de uma ordem social pautada pelo acesso universal a cultura elaborada". (SERDEIRA, 2019, p. 193) 
É aqui que se determina a concepção de mundo mais clara da parte do professor e da parte do aluno, principalmente deste último. Por ainda não possuir a disciplina e esforço necessários para a apreensão da cultura elaborada, faz-se preciso a constituição de um universo específico e especial de formação. A escola, portanto, é esse espaço que exige a disciplina e a construção de hábitos intelectuais, ao mesmo tempo em que oferece acesso às obras canônicas da cultura elaborada. E cultura elaborada não é sinônimo, necessariamente, de cultura eurocêntrica. É evidente que a análise de Snyders se faz sobre a escola francesa, no entanto, o que se entende por cultura elaborada é, sobretudo, o conjunto de saberes da cultura letrada e aqueles bens artísticos que constituem um patrimônio histórico-cultural.

No processo de reelaboração do senso comum a partir das categorias da cultura elaborada, Snyders, de maneira muito parecida com Arendt, ressalta o caráter fulcral da posição do adulto como responsável por colocar a criança em contato com os bens culturais do mundo. Dessa maneira,

A necessidade de elaborar concepções de mundo mais claras exigiria um papel ativo por parte do professor e também por parte do aluno: esforço intelectual, estudo rigoroso e desenvolvimento de hábitos de leitura e investigação que ainda não possui, no entanto, todo homem está naturalmente apto. Daí a importância de um universo especialmente construído para formar intelectualmente a criança em um duplo sentido: exigindo-lhe disciplina e construção de hábitos intelectuais e oferecendo-lhe acesso às maiores obras da cultura universal. (SERDEIRA, 2019, p. 194)

A alegria, nesse sentido, viria do acesso sistemático à cultura elaborada, mediado pela escola. E essa escola de Snyders que, embora ressignifique elementos identificados como da escola tradicional, dela se diferencia ao ter como pressuposto a primazia do presente: não se trata de elaborar o currículo e planejar as ações pedagógicas com vistas apenas ao futuro. A escola snydersiana é comprometida com a alegria no presente e essa alegria se traduz na satisfação singular que vem por meio de um contato com a cultura elaborada pautado na disciplina e no esforço intelectuais. De acordo com o autor, 
A cultura dá satisfação - quero afirmar que a cultura dá satisfação, ou melhor, que há culturas capazes de dar satisfação. Isso significa que a caminhada em direção à verdade, à apreensão do real, dá mais satisfação, abre mais esperança que permanecer na incoerência, no aproximativo, indeciso. Isso significa também que a satisfação da cultura pode e deve culminar em ação que mude alguma coisa no mundo, participe às forças que mudam algo no mundo. Em suma, a alegria da cultura como que fortalecendo a confiança em mim mesmo, confiança na vida: amar mais um mundo, aprendê-lo como mais estimulante, mais acolhedor. (SNYDERS, 1988, p. 19-20)

Serdeira (2019) traz um aspecto relevante de sua análise sobre a alegria e satisfação da cultura em Snyders, a saber, a da utopia do autor em relação à escola enquanto um espaço que pode fomentar a igualdade, a democracia e promover uma cultura com menos preconceitos, uma vez que constitui tempo-espaço de construção individual e de reelaboração cultural. Assim, a comentadora explicita características fundantes do pensamento de Snyders e de sua concepção da escola como um espaço de satisfação individual e de consolidação da cultura - visto que esta é internalizada mais por meio de estruturas intelectuais do que através da reprodução de modelos operacionais. Esses princípios fundamentais são:

1) para transformar, é preciso conhecer o objeto de transformação e, por isso, 2) os adultos tem que assumir a responsabilidade de apresentar às crianças esse mundo que lhes é totalmente novo, inusitado e encantador, utilizando obras historicamente construídas, para que, dessa forma, possam transformar sua concepção de mundo e, por meio dela, suas condições de vida. (SERDEIRA, 2019, p. 195)

Alegria e satisfação, portanto, se dariam, em Snyders, a partir da mediação do adulto no contato e relação da criança com a cultura elaborada, e isso, em um universo específico, construído historicamente. Nesse universo escolar, as obras culturais são tomadas como base para a apresentação de modelos morais e intelectuais para as crianças e jovens. A alegria não consistiria no prazer imediato. Muito pelo contrário. Como já é possível compreender, a alegria na escola é mediada e exige a aquisição de certa disciplina intelectual, a qual é desenvolvida no tempo-espaço específico da instituição escolar. Essa alegria e satisfação tão peculiares vinculam-se, de 
maneira mais elementar, ao presente, ao pertencimento, à noção de cultura aberta a todos, e, de forma mais complexa, à racionalidade, ao esforço e ao contato com o conhecimento historicamente acumulado. (SERDEIRA, 2019, p. 197)

Nos escritos de Snyders (1988), é possível perceber a preocupação que o autor tem com a formação pessoal dos jovens durante o período escolar, ou seja, não apenas o pleno aprendizado dos conteúdos passados, mas com o desenvolvimento de jovens conscientes, cultos e principalmente, felizes consigo mesmo e com as suas produções. Considerando que a alegria e a satisfação, como já foi dito, só são possíveis em face da imersão na cultura mediada pela escola, o pedagogo francês propõe uma distinção importante entre cultura primeira e cultura elaborada. Segundo ele,

Há muitas alegrias que não têm necessidade do sistemático Há formas de cultura que são adquiridas fora da escola, fora de toda autoformação metódica e teorizada, que não são o fruto do trabalho, do esforço, nem de nenhum plano: nascem da experiência direta da vida, nós a absorvemos sem perceber; vamos em direção a elas seguindo a inclinação da curiosidade dos desejos; eis o que chamarei de cultura primeira. [... As] alegrias da vida cotidiana, alegrias da cultura de massa: essas são verdadeiras alegrias; não tenho absolutamente a intenção de enfraquecê-las, mas tentarei dizendo que elas me parecem insuficientes e isso em relação às suas próprias promessas. Sustentarei que é a cultura elaborada que pode, melhor do que a cultura primeira, atingir os objetivos, isto é, finalmente, as satisfações da cultura primeira. (SNYDERS, 1988, p. 23)

No pensamento snydersiano, é estabelecido um contorno da realidade e do presente que se tenta ressignificar, reinterpretar a partir da cultura elaborada, a qual o autor concebe como a alegria cultural. Ou seja, ele pensa sobre a alegria da cultura primeira, mais espontânea, e a alegria da cultura elaborada. Esta última, por não se restringir aos limites da realidade do sujeito, permite à escola se estabelecer no presente, a oferecer ferramentas intelectuais para reconstruir a realidade, baseando-se em outros significados e experiências possíveis no mundo. As alegrias da cultura possibilitariam aos jovens e crianças se estabelecerem no mundo, de modo que o passado ajudaria a desvelar o presente e a construir o futuro. Destarte, 
[… obra cultural é uma colocação em comum, nunca uma realização isolada, fechada em si mesmo; cada uma é testemunha da sucessão humana de um grau, por assim dizer, total da sucessão humana. Eis uma das alegrias que nela experimento: sinto viver um patrimônio comum, não abordo uma Ilhota arbitrária. A cultura para que eu sinta a história como ponto de apoio; não estou perdido na imensidão dos tempos, o mundo é histórico, isto é, movimento e transformação, o contrário do repetitivo, do imutável - ou do caótico; ele pode e deve ser renovado. (SNYDERS, 1988, p. 50)

O pedagogo francês defende, ainda, que as metodologias de ensino não devem ser tão rígidas, tradicionais e inflexíveis quando tratamos com crianças e jovens em formação. Para o autor, tais metodologias não condizem com a etapa vivida pelos alunos, onde há descobrimento, desenvolvimento e a formação de novas opiniões e gostos.

\section{Cantigas tradicionais como legado histórico-cultural}

O debate acerca da noção de cultura popular é vasto e complexo, tendo sido pautado por diferentes vertentes da antropologia, da história e de outras áreas das ciências humanas. Este artigo não pretende adentrar a essa discussão, no entanto, considerando-se que o objetivo é pensar a importância das cantigas tradicionais na escola - tendo-se como premissa a função social da instituição escolar de transmitir às novas gerações um patrimônio cultural historicamente acumulado e dar-lhes elementos para a fruição daquilo que Snyders chamou de cultura elaborada - faz-se necessário elucidar o que se entende aqui por cultura popular. Ao disserta sobre as cantigas tradicionais, compreende-se que:

Cultura popular não é um conjunto fixo de práticas, objetos ou textos, nem um conceito definido aplicável a qualquer período histórico. Cultura popular não se conceitua, enfrentase. É algo que precisa sempre ser contextualizado e pensado a partir de alguma experiência social e cultural, seja no passado ou no presente; na documentação histórica ou na sala de aula. O conceito só emerge na busca do como as pessoas comuns, as camadas pobres ou os populares (ou pelo menos o que se considerou como tal) enfrentam (ou enfrentaram) as novas modernidades (nem sempre tão novas assim); de 
como criam (ou recriaram), vivem (ou viveram), denominam (ou denominaram), expressam (ou expressaram), conferem significados (ou conferiram) a seus valores, suas festas, religião e tradições, considerando sempre a relação complexa, dinâmica, criativa, conflituosa e, por isso mesmo, política mantida com os diferentes segmentos da sociedade: seus próprios pares, representantes do poder, reformadores, professores etc. Não se deve perder de vista a reflexão sobre as possibilidades destas manifestações encontrarem-se relacionadas com as lutas sociais e políticas mais amplas da sociedade a que pertencem (ou pertenceram). (ABREU, 2003, p. 13)

Ora, partindo-se da ideia que a cultura popular se constitui por meio de um conjunto de lutas e conflitos sociais que se relacionam com questões culturais as quais delineiam formas de criar a identidade cultural a partir de significados sociais distintos, pode-se afirmar também que a cultura popular é tecida a partir do diálogo e da potência dos diferentes grupos e sujeitos para fazer emergir uma transformação da consciência individual e coletiva, tendo como efeito a crítica e a criatividade das culturas como produto da participação dos atores que a vivenciam e a produzem. Assim, a educação é um dos movimentos que auxiliam a promover uma ruptura com os padrões vigentes para "Construção de uma sociedade igualitária que acolhesse, gerisse e transformasse dialeticamente culturas democraticamente libertadas e ativamente libertadoras". (BRANDÃO et al., 2009, p. 735)

Nesse sentido, embora sabido que o conceito de cultura popular e o agenciamento desse tema no debate acadêmico, educacional e político é atravessado de contradições, tensões e rupturas, neste trabalho, entende-se que a cultura popular não é uma categoria oposta àquilo que se denomina como cultura erudita e que popular não é o mesmo que de massas. A cultura popular, portanto, tem a ver com a produção cultural de atores e coletivos populares que se inserem nas tradições de uma comunidade e povo, ressignificando-as e dotando-as de sentido público. É com base nessa compreensão geral que as cantigas tradicionais são abordadas nas linhas que se seguem. Isso é, como elementos da cultura popular que integram um legado a ser transmitido e ressignificado histórica e socialmente.

As cantigas tradicionais vêm sendo passadas de geração em geração como forma de perpetuar práticas lúdicas e musicais por meio da oralidade. Entende-se como cantigas, 
[...] canções utilizadas em brincadeiras de roda cantada, realizadas como forma de recreação por adultos e crianças. Sua formação clássica consiste em formar uma roda de mãos dadas, com o rosto voltado para o centro, movimentando-se para a direita ou para a esquerda, em andamento eleito pelo grupo. (MAFFIOLETTI, 1994, p. 15)

Maffioletti e Rodrigues (1992) explicam sobre os efeitos que as cantigas de roda criam nas linguagens individuais e grupais. De acordo com as autoras, "as diferentes linguagens - corporal, musical e cênica - permitem aprendizagens cognitivas, afetivas e sociais nas diferentes áreas do conhecimento". (MAFFIOLETTI; RODRIGUES, 1992, p. 19) Nesse sentido, a cantiga é um tipo de música que gera movimento e traz consigo a carga dos significados sociais de cada gesto que é feito. A imagem transforma o ato de cantar em uma representação, um mundo imaginário no qual a criança pode explorar sua criatividade e que reflete em um jogo simbólico, trazendo ao centro o aspecto lúdico, o que faz a música ser o brinquedo que dá suporte à brincadeira e ao mesmo tempo seja a própria brincadeira, desvelando seu duplo valor social. (MAFFIOLETTI; RODRIGUES, 1992)

Ao considerar as cantigas como uma produção cultural que coaduna as dimensões da musicalidade, ludicidade e coletividade, entende-se que estas se constituem como "[...] As primeiras experiências coletivas de exploração dos espaços internos e externos". (MAFFIOLLETTI; RODRIGUES, 1992, p. 17) Embora assim o seja, Santos (2010), ao analisar a presença das cantigas de roda na escola, mostrou que elas são pouco exploradas no cotidiano e que há resistência de professores e alunos para a realização de atividades que envolvam as cantigas. A autora disserta sobre a importância dessas manifestações culturais tradicionais no ambiente escolar, compreendendo-as como parte fundamental do trabalho pedagógico, uma vez que constituem conteúdo importante na formação sociocultural das crianças.

Situadas no universo específico de formação das crianças, as cantigas tradicionais, para além de um momento de recreação, possibilitam a transmissão da história dos antepassados, saberes, conhecimentos e práticas corporais populares que há muito tem se perpetuado de geração em geração. Considerando o modo de vida urbano e a ruptura do fio da tradição no mundo moderno, percebe-se que muitos dos saberes populares, antes transmitidos oralmente 
no contexto das comunidades e agrupamentos culturais, tendem a se perderem no esquecimento. A especialização e fragmentação do conhecimento, a perda da organização comunitária e do senso de pertencimento a uma comunidade, o pathos do novo que produz a desvalorização do passado e a obsolescência de saberes tradicionais populares são alguns elementos das sociedades contemporâneas que reforçam a necessidade de que a escola, como instituição que se interpõe entre o público e o privado e o passado e o futuro, possa ser o tempo-espaço que coloca as novas gerações em contato com a cultura tradicional das cantigas.

Santos (2010) apresenta o contexto histórico do surgimento das cantigas, explicando que elas eram reconhecidas coletivamente e que se estruturaram em meio à cultura regional de onde se originaram, já constituindo, de início, significado educativo e modos de fabulação nas comunidades em que se desenvolveram. Dessa forma,

A origem das Cantigas de Roda acaba se misturando com a própria história da humanidade por estar presente nas esquinas de cada região, cada país, cada continente e se tornado de domínio popular e considerada como parte da cultura de vários povos. Estas cantigas movimentam e estimulam a fantasia, levando-nos ao mundo do faz de conta, cheias de lendas, crenças, mitos, personagens, cores, etnias e até fatos históricos, revelando a essência da alma de um povo, funcionando como ferramenta de entretenimento, influenciando na formação e informação do indivíduo. (SANTOS, 2010, p. 18)

As cantigas, portanto, fazem parte da cultura das comunidades e regiões nas quais se originaram, sendo representações simbólicas e laços de pertencimento territoriais e culturais. Elas evidenciam traços da experiência coletiva de vida humana que existe em cada local. No que diz respeito ao Brasil, "A maioria das cantigas de roda é proveniente de outros países e passaram por modificações culturais, adaptando-se e tornando-se populares", sendo hoje parte do cabedal cultural brasileiro. (SANTOS, 2010, p. 18) As cantigas, portanto, são atravessadas dos processos de hibridização cultural entre os diferentes povos, regiões e práticas lúdicas comunitárias.

A música, o canto, as danças e festas são definidos como manifestações culturais, expressas através de linguagens artísticas em acontecimentos como: festividades religiosas, danças, jogos, brincadeiras e cantos. Todas essas manifestações 
têm origens em outros países, que em épocas passadas foram trazidas ao Brasil e aqui permaneceram como herança cultural até os dias atuais, carregadas de valores, visões e comportamentos diferentes, guardados na lembrança do povo brasileiro. (SANTOS, 2010, p. 19)

As cantigas, dessa maneira, são produto de uma construção social, pois foram criadas para expressar a vida, a sociedade, o vínculo com o território e com a comunidade, bem como as situações vivenciadas pelos adultos nesse universo cultural. Em virtude disso, Santos (2010) entende que as cantigas não podem ser analisadas fora de seu contexto histórico, pois se fundamentam nas construções e manifestações de uma população. Constituem, portanto, parte do legado histórico-cultural de um povo e, por isso, são objetos culturais a serem disseminados pela escola, uma vez que esta é a instituição que tem por função mediar a relação das crianças com a cultura, introduzi-las no mundo humano e, por meio da seleção de fragmentos do passado, salvar da ruína e do esquecimento aquilo que se considera valioso e desejável de ser transmitido como herança para as novas gerações. Com efeito,

As Cantigas de Roda no universo escolar são vistas como parte essencial na vida das crianças, pois contribuem para a formação sociocultural das mesmas. A cultura é esse constante aprendizado, ensinamento; a interação de conhecimentos científicos ou populares, filosóficos ou religiosos existentes em uma determinada sociedade. É a partir das relações sociais estabelecidas entre as pessoas que se constroem os conhecimentos e se formam os padrões sociais. (SANTOS, 2010, p. 24)

No seu aspecto cultural, as cantigas dotam de significado histórico o seu conteúdo cantado, presentificando a história das comunidades humanas em que se originaram e estabelecendo ligação entre as novas gerações e as gerações precedentes. No que diz respeito ao contexto brasileiro em que o currículo escolar, por muito tempo, permaneceu (e por que não dizer que ainda insiste em permanecer) fundamentado em uma visão eurocêntrica do mundo, a apresentação de cantigas que integrem a diversidade de manifestações culturais dos povos indígenas e da população negra também provoca o tensionamento e a disputa de significados estéticos, éticos, epistemológicos e simbólicos. Por isso, abster-se 
de preservar esses objetos imateriais da cultura consiste em assumir o risco do seu desaparecimento e, como ele, o apagamento de uma parte do mundo. Mundo este não no sentido espacial, mas no sentido de universo simbólico e patrimônio cultural historicamente acumulado.

\section{Considerações finais}

Com Arendt é possível entender a crise na educação sob a perspectiva da crise do mundo moderno, de modo que a atividade educativa é situada pela autora em uma aporia: se dá em um contexto em que houve a ruptura com o fio da tradição e a perda da autoridade e, ao mesmo tempo, não pode abrir mão nem da tradição e nem da autoridade. Em vista disso, a filósofa concebe o sentido da educação na chegada de novos seres humanos ao mundo pelo nascimento, exigindo dos adultos a inserção desses novos no conjunto de saberes, histórias, hábitos, valores, símbolos, artefatos que constituem o mundo.

A criança é, portanto, inserida nesse mundo e, espera-se que ela, futuramente, assuma a responsabilidade em dar continuidade a ele e, quiçá, renová-lo por meio da ação política. É nesse sentido que Arendt concebe a escola como instituição entre, ou seja, como aquela que se localiza em uma esfera pré-política, situada entre a esfera privada da família e a esfera pública da política. À escola caberia essa transição do lar para o mundo, mesmo que, efetivamente, ela jamais imite ou se assimile àquele ou a esse. Dessa maneira, ao propor sua concepção de educação, Arendt não se preocupa em elencar as finalidades dessa atividade, mas se dispõe a pensar um possível sentido da relação intergeracional que é estabelecida na inserção da criança no mundo e da transmissão de um legado histórico-cultural.

É aqui que, de acordo com a argumentação apresentada neste artigo, a proposta arendtiana se entrelaça com as ideias de Snyders. Para o pedagogo francês, a escola, a partir das relações intersubjetivas que nela se estabelecem mediadas pelos objetos da cultura, assume uma função social que a define como um universo específico, onde a criança pode obter a alegria do conhecimento. Isso é assim, pois, a escola coloca a criança em contato com a cultura elaborada e é nesse mesmo lugar que ela adquire disciplina para imergir nessa cultura, a partir da disciplina e do esforço intelectual. 
Snyders aborda a noção de cultura elaborada, o que o aproxima de Arendt, uma vez que ambos analisam a responsabilidade dos adultos em inserir a criança na cultura e permitir, com isso, o acesso das novas gerações aos bens culturais do mundo.

A alegria do conhecimento se dá, em Snyders, pelo acesso sistemático à cultura elaborada, o que é feito pela escola. E essa escola que possibilita a alegria só o faz ao entender sua ação no presente, por meio da satisfação singular que produz a partir do contato com a cultura pela disciplina e esforço intelectuais, com papel ativo do professor e do aluno.

Em face disso, as cantigas são compreendidas na argumentação aqui proposta como objetos culturais a serem transmitidos a partir de práticas lúdicas e musicais que vão além de um momento de recreação, o que permite também a transmissão da história e das práticas populares que se perpetuam de geração em geração e que são parte da tradição. Em um contexto educacional no qual a inovação, a novidade e a instrumentalidade dão forma às críticas acerca da obsolescência da escola, este artigo buscou debater um possível sentido da atividade educativa e a importância da transmissão dos saberes tradicionais, em especial das cantigas, como parte da inserção das crianças e jovens no mundo.

\title{
Education, transmission, and culture: traditional songs as a historical-cultural legacy in the school context
}

\begin{abstract}
This article seeks to discuss traditional songs at school as a way of transmitting a historical-cultural legacy, starting from the concept of education proposed by Hannah Arendt and the notion of joy at school by Georges Snyders. Through a bibliographical review and analysis of the thoughts of both authors about the meaning of educational activity, the social and political function of the school and the concept of tradition and culture, it is intended to discuss the importance of transmitting a historical and cultural heritage, coming from popular knowledge and knowledge, of which traditional songs are part. Hannah Arendt understands education as an activity of insertion and initiation of new generations in the world through the transmission of knowledge, habits, values and knowledge. Snyders, in turn, thinks of the school as a social and cultural space where the child's contact with the elaborated culture and traditions occurs. This is, for the French author, what would characterize the school as a specific universe, in which, through discipline and intellectual effort, one would have access to the joy of knowledge and the satisfaction of culture. Given this approximation of Arendt's and Snyders' thought, it is concluded that, in view of the rupture of the thread of tradition in the modern world, the transmission of knowledge and playful practices of popular culture, such as traditional songs, is fundamental for the new
\end{abstract}


generations establish bonds of belonging with the world and dialogue with the past and with previous generations.

keywords: school; culture; traditional songs; Hannah Arendt; Georges Snyders.

\section{Educación, transmisión y cultura: el canto tradicional como legado histórico-cultural en el contexto escolar}

Resumen: Este artículo busca debatir las canciones tradicionales en la escuela como una forma de transmitir un legado histórico-cultural, a partir del concepto de educación propuesto por Hannah Arendt y la noción de alegría en la escuela de Georges Snyders. A través de una revisión bibliográfica y análisis del pensamiento de ambos autores sobre el significado de la actividad educativa, la función social y política de la escuela y el concepto de tradición y cultura, se pretende discutir la importancia de transmitir un patrimonio histórico y cultural, provenientes de saberes y saberes populares, de los que forman parte las canciones tradicionales. Hannah Arendt entiende la educación como una actividad de inserción e iniciación de las nuevas generaciones en el mundo a través de la transmisión de conocimientos, hábitos, valores y saberes. Snyders, a su vez, piensa en la escuela como un espacio social y cultural donde se produce el contacto del niño con la cultura y las tradiciones elaboradas. Esto es, para el autor francés, lo que caracterizaría a la escuela como un universo específico, en el que, a través de la disciplina y el esfuerzo intelectual, se accedería al gozo del conocimiento y la satisfacción de la cultura. Dada esta aproximación al pensamiento de Arendt y Snyders, se concluye que, ante la ruptura del hilo de la tradición en el mundo moderno, la transmisión de conocimientos y prácticas lúdicas de la cultura popular, como las canciones tradicionales, es fundamental para las nuevas generaciones establecen vínculos de pertenencia con el mundo y dialogan con el pasado y con las generaciones anteriores.

Palabras clave: escuela; cultura; canciones tradicionales; Hannah Arendt; Georges Snyders.

\section{Referências}

ABREU, M. Cultura popular, um conceito e várias histórias. In: ABREU, M.; SOIHET, R. Ensino de história, conceitos, temáticas e metodologias. Rio de Janeiro: Casa da Palavra, 2003.

ARENDT, H. A crise na educação. In: ARENDT, H. Entre o passado e o futuro. São Paulo: Perspectiva, 2003.

ARIÈS, P. História social da infância e da família. Rio de Janeiro: LTC, 1981.

BRANDÃO, C. R.; ASSUMPÇÃO, R. Cultura rebelde: escritos sobre a educação popular ontem e agora. São Paulo: Editora e livraria Instituto Paulo Freire, 2009.

CUSTODIO, C. de O. Educação e mundo comum em Hannah Arendt: reflexões e relações em face da crise do mundo moderno. 2011. Dissertação (Mestrado em Educação) - Faculdade de Educação, Universidade de São Paulo, São Paulo, 2011. Disponível em:

doi:10.11606/D.48.2011.tde-04072011-144919. Acesso em: 23 jul. 2020. 
LEITE, T. de C. Teatro como experiência formativa: um diálogo com o pensamento de Hannah Arendt. 2016. Dissertação (Mestrado em Educação) - Faculdade de Educação, Universidade de São Paulo, São Paulo, 2016. Disponível em: https://www.teses.usp.br/teses/ disponiveis/48/48134/tde-08092016-153359/pt-br.php. Acesso em: 26 jul. 2020.

MAFFiOletTI, L.; RODRIGUES, J. Cantigas de roda. Porto Alegre: Magister, 1992.

SANTOS, B. do S. M. Cantigas de Roda: o Resgate Popular na Formação Sociocultural do Aluno. 2010. Dissertação (Mestrado em Ciências da Educação) - Universidade de Évora, Évora, 2010. Acesso em: 03 ago. 2020.

SERDEIRA, A. H. I. de C. A obra de Georges Snyders: cultura e política como pressupostos de uma escola progressista. In: BOTO, C. (org.). Clássicos do Pensamento Pedagógico: olhares entrecruzados. Uberlândia: EDUFU, 2019.

SNYDERS, G. Alegria na escola. São Paulo: Manole, 1988. 